As a preliminary result, such experimental evidence seems to support a close relationship between volcanism and climate, with a sensitivity of volcanic activity to fast temperature changes. This could point to a relevant role of changes in cryosphere and hydrosphere systems (growing or melting of polar ice sheets with consequent change of sea level) in controlling volcanic activity. On the other hand, the fact that the highest number of events are recorded during the two last millennia, something common to several Antarctic ice cores (Castellano et al., 2005), when climatic conditions have been relatively stable, raises new hints and questions for future discussions.

\section{References}

Castellano, E., Becagli, S., Jouzel, J., Migliori, A., Severi, M., Steffensen, J.P., Traversi, R. and Udisti, R., 2004. Volcanic eruption frequency in the last $45 \mathrm{kyr}$ as recorded in EPICA-Dome C ice core (East Antarctica) and its relationship to climate changes. Glob. Planet. Change, 42, 195-205.
Castellano, E., Becagli, S., Hansson, M., Hutterli, M., Petit, J.R., Rampino, M.R., Severi, M., Steffensen, J.P., Traversi, R. and Udisti, R., 2005. Holocene volcanic history as recorded in the sulphate stratigraphy of the European Project for Ice Coring in Antarctica Dome C (EDC96) ice core. J. Geophys. Res., 110, D06114, doi: $10.1029 / 2004 J B 005259$.

EPICA community members, 2004. Eight glacial cycles from an Antarctic ice core. Nature, 429, 623-628.

Udisti, R., Becagli, S., Castellano, E., Mulvaney, R., Schwander, J., Torcini, S. and Wolff, E.W., 2000. Holocene electrical and chemical measurements from the EPICA - Dome C ice core. Ann. Glaciol., 30, 20-26.

Udisti, R., Becagli, S., Castellano, E., Delmonte, B., Jouzel, J., Petit, J.R., Schwander, J., Stenni, B. and Wolff, E.W., 2004. Holocene electrical and chemical measurements from the EPICA - Dome C ice core. J. Geophys. Res., 30, 20-26.

\title{
Secular variability and 200-year diploar oscillations in an atmospheric circulation over East Antarctica during the Holocene
}

\section{B. Delmonte' ${ }^{1}{ }^{2}$, J.R. Petit' ${ }^{2}$, V. Maggi ${ }^{2}$}

'Laboratoire de Glaciologie et de Géophysique de l'Environnement, Saint Martin d'Hères, France. bdelmonte@nest.it

2Department of Environmental Sciences University Milano-Bicocca, Milano, Italy.

Deep ice cores from the East Antarctic Plateau are unique archives of climate history spanning the Late Quaternary (e.g. EPICA Community Members, 2004; Petit et al., 1999). Insoluble, long-range windblown mineral dust from the Southern Hemisphere continents to the East Antarctic Plateau and archived in the ice layers can be used as a tracer for documenting environmental and atmospheric circulation changes in the Southern Hemisphere at different time scales.

Dust mainly consists of the terrigenous minerals clay, quartz and feldspars. The total concentration in polar ice depends on numerous factors, such as source strength, hydrological cycle, residence time of aerosols, atmospheric transport and snow accumulation rate on the ice sheet. Interestingly, ice core investigations from East Antarctica showed that the grain-size of aeolian minerals is a very useful indicator for atmospheric transport, displaying modes of variability independent from the total dust input (Delmonte et al., 2004). Looking at ice core dust data from these two complementary points of view opens up new perspectives towards improved documentation and better understanding of the dynamics induced by climate forcing at high southern latitudes over the late Quaternary.

A recent dust investigation of two ice cores from East Antarctica (Fig. 1), one from EPICA Dome C (EDC, $75^{\circ} 06^{\prime} \mathrm{S}$ $123^{\circ} 21^{\prime} \mathrm{E}$ ), the other from Vostok (Vostok-BH7, $78^{\circ} 28^{\prime} \mathrm{S}$ $\left.106^{\circ} 48^{\prime} \mathrm{E}\right)$ allowed the depiction of secular and multisecular modes of dust size and atmospheric circulation variability during most of the Holocene (Delmonte et al., 2005). The dust concentration and size profiles along with the water stable isotope content, reported in Fig 1, display clear differences. The total dust input in Antarctic ice is tightly related to environmental conditions at the source regions and a good example is the $~ 800-1,000-$ year-long dust minimum occurring before the Holocene onset (between 12 and 11 kyr BP), likely related to humid conditions in South America, the dominant dust source region for the Antarctic Plateau. Such an event was also found in two other East Antarctic ice cores (Delmonte et al., 2004) and may represent a robust stratigraphic marker. After this event, both EDC and Vostok records display a short-term variability superposed on a main Holocene decreasing trend.

The patterns of dust size changes from both cores (Fig. 1c and $1 \mathrm{~d}$ ) are clearly different with respect to concentration profiles and characterised by a high-frequency (secular to sub millennial) mode of variability. Also, there are evident discrepancies between Vostok and EDC dust size records and the short-term (secular-scale) variations are differently structured in apparent multi-secular and millennial-scale cycles in the two records.

Spectral analyses of the two dust size series for the period of overlap (9.8 to $3.5 \mathrm{kyr} \mathrm{BP}$ ) pointed out significant secularscale periodical modes of variability and an interesting common periodicity around $\sim 200$ years.

A series of volcanic markers randomly distributed over the common part of the records allowed the establishment of a tight stratigraphic and chronological link ( \pm 30 years) between the two records. Interestingly, dust size changes are often asynchronous and out of phase. With respect to the 200-year component, in particular, dust size changes appear out of phase (over 25 cycles from a total of 29) for about 5.5 kyr duration between 9.8 to $4.2 \mathrm{kyr}$ BP.

\section{Regional variability of dust transport and atmospheric circulation patterns over East Antarctica}

The slight dust size fractionation observed in polar ice should depend mostly on transport time and it is likely insensitive to air temperature or water saturation pressure. Therefore, grain-size changes could be associated with the 


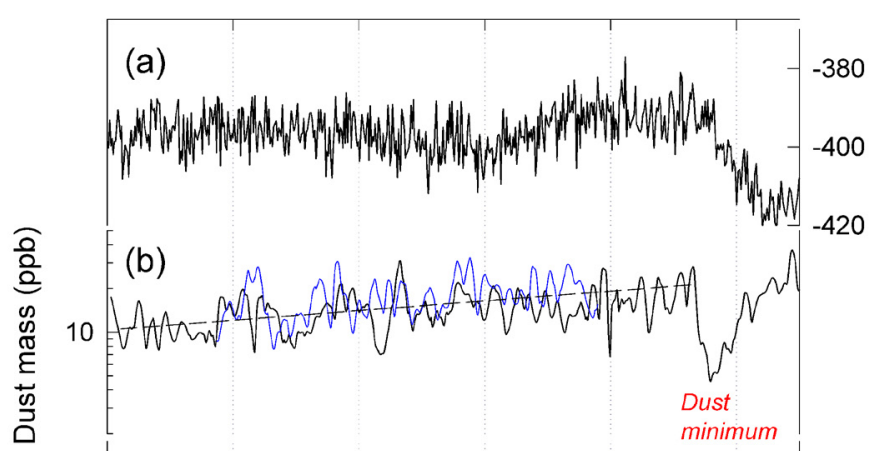

(c)

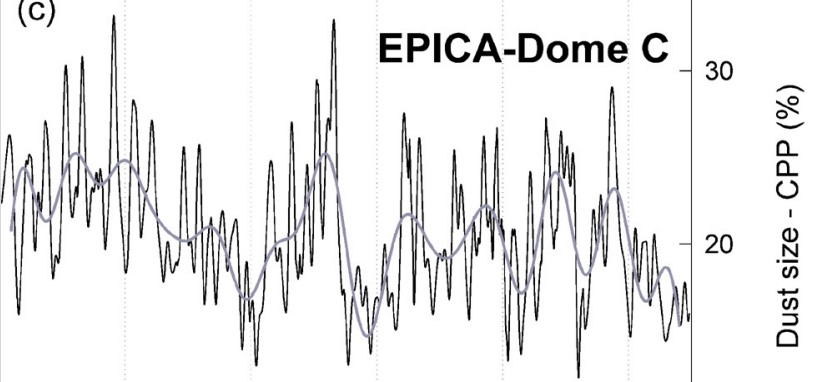

(d)

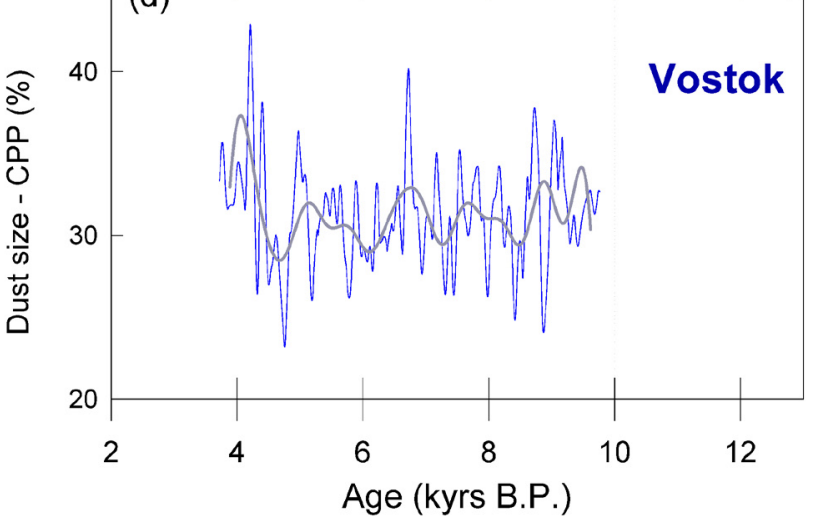

variability of atmospheric transport pathways. Fine dust is likely related to subsidence and sinking from upper air and/or to longer trajectories, while relatively coarse dust size indicates advection of air masses from lower levels in the troposphere.

While southern South America is the dominant source for the glacial period, the dust source regions are not well constrained for the Holocene period. Therefore, the asynchronous dust size variations can possibly be attributed to different transport paths from a common dust source or to an alternate influence of two or more sources on one site or the other. Whatever the cause, the differences observed between the two East Antarctic sites, which are only 600 $\mathrm{km}$ apart on the Plateau, suggest a regional (mesoscale) variability of atmospheric circulation regimes.

The out-of-phase changes between the two sites depicted in the common 200-year band of variability suggest that an asymmetric (or dipolar) mode of variability was operating over East Antarctica during most of the Holocene. Indeed, regional differences of dust size and atmospheric circulation changes between the EDC-Komsomolskaya region and the Dome B-Vostok region were also unequivocally observed during the last glacial maximum to Holocene transition (Delmonte et al., 2004). These were interpreted as being related to the general reorganisation of the atmospheric circulation during the climatic transition, linked also to Southern Ocean conditions, and leading to a gradual change in the eccentricity of the polar vortex (i.e., the distance of its centre from the geographical south pole).
Fig. 1: Holocene records from Vostok and EDC ice cores (from

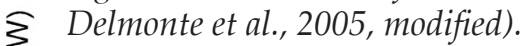

(a) EDC Deuterium record ( $\delta D$ expressed in \%o with respect to Vienna-SMOW), from Jouzel et al., 2001.

(b) Total dust mass concentrations ( $p p b$ or $10^{-9} \mathrm{~g} / \mathrm{g}$ ) from EDC (black line) and Vostok (blue line) ice cores, analysed with a time resolution of about 1 sample per $~ 50$ years (running average over 70 years). The pre-Holocene dust minimum is indicated (12-11 kyr BP) along with the general Holocene decreasing tendency of the series (dashed line).

(c) EDC dust size record (running average and lowpass filtered data for periodicities shorter than 1,000 years), expressed as Coarse Particle Percentage (CPP, \%) of the total dust mass. As particles are typically smaller than $5 \mu \mathrm{m}$ in diameter, the CPP parameter was calculated in the 3-5 $\mu \mathrm{m}$ interval for EDC.

(d) The same as (c) but for the Vostok ice core. Coarse particles were calculated in the 2.5-5 $\mu \mathrm{m}$ diameter interval, as dust in the Vostok ice core is slightly smaller.

\section{The 200-year mode of variability}

The relative chronology of the two records was tightened by volcanic markers, allowing simple combinations of dust size parameters. The sum $(\Sigma)$ and the difference $(\Delta)$ of EDC and Vostok CPP parameters allowed the construction of two composite indicators suitable for characterising the symmetric $(\Sigma)$ and the asymmetric $(\Delta)$ mode of atmospheric circulation variability, respectively. On the one hand, the symmetric mode, which could be associated with the strength of the Antarctic Oscillation, contains a continuum of periodicities spread from 140 to 500 years (Fig 2a), likely reflecting oscillations of the Southern Ocean climatic system. On the other hand, the $\Delta$ (asymmetric) parameter is associated with the relative difference of air mass influencing Vostok and EDC regions, and contains pronounced secular-scale modes of variability around 200 years (Fig 2).

The 200-year periodicity is of particular interest as it is usually associated with the variability of solar activity (205year, so-called DeVries solar cycle) and is one of the most prominent periodicities in the Holocene $\Delta^{14} \mathrm{C}$ record, and is also imprinted in the ${ }^{10} \mathrm{Be}$ record of polar ice (e.g. Beer et al., 1991). Indeed, the solar climate connection could likely be mediated by the Southern Ocean system, this later playing the role of "pseudo-oscillator", integrating, amplifying and embedding into its internal variability mode a possible external forcing. The 200-year band of variability strongly expressed in the atmospheric (dust size) records from Vostok and EDC might represent the final expression of an 
ocean-atmosphere amplification of solar forcing at secular periodicities, influencing sea surface temperature, sea ice extent and the climatological position of highs and lows. Finally, the climatic response on the East Antarctic can be expected to be delayed with respect to solar forcing, as the Southern Ocean and sea ice cover introduce thermal inertia into the system.

Model studies of atmosphere-ocean-sea ice interactions, along with the study of the regional impacts of solar forcing, as well as ${ }^{10} \mathrm{Be}$ concentration measurements from Vostok or EDC ice core samples, will be very helpful in documenting this relationship and testing such speculations.

\section{Acknowledgements}

The work of B. Delmonte was supported by a 2003 Prince of Asturias Fellowship awarded by SCAR and benefited from a Balzan donation to C. Lorius. The Vostok ice core (BH7 and 8) was obtained through the Russia-US-France tripartite collaboration and benefited from the support of Russian Antarctic Expeditions, the US NSF and the French Paul Emile Victor Institute. This work is a contribution to the European Project for Ice Coring in Antarctica, a joint ESF/EC scientific programme funded by the European Commission under the Environmental and Climate Programme (1994-1998) contract ENV4-CT95-0074 and by national contributions from Belgium, Denmark, France, Germany, Italy, the Netherlands, Norway, Sweden, Switzerland and the UK.

\section{References}

Delmonte, B., Petit, J. R., Andersen, K. K., Basile-Doelsch, I., Maggi, V., Lipenkov, V., 2004. Dust size evidence for opposite regional atmospheric circulation changes over East Antarctica during the last climatic transition. Climate Dynamics 23, 427-438.

Delmonte, B., Petit, J. R., Krinner, G., Maggi, V., Jouzel, J., Udisti, R., 2005. Ice core evidence for secular variability and 200-year dipolar oscillations in atmospheric circulation over East Antarctica during the Holocene. Climate Dynamics, DOI 10.1007 / s00382005-0012-9.

EPICA Community Members, 2004. Eight glacial cycles from an Antarctic ice core. Nature 429, 623-628.

Jouzel, J., Masson, V., Cattani, O., Falourd, S., Stievenard, M., Stenni, B., Longinelli, A., Johnsen, S. J., Steffensen, J. P., Petit, J. R., Schwander, J., Souchez, R., 2001. A new 27 kyr high resolution East Antarctic climate record. Journal of Geophysical Research 28, 3199-3202.

Petit, J. R., Jouzel, J., Raynaud, D., Barkov, N. I., J.M.Barnola, Basile, I., Bender, M., Chappellaz, J., Davis, M., Delaygue, G., Delmotte, M., Kotlyakov, V. M., Legrand, M., Lipenkov, V. Y., Lorius, C., Pépin, L., Ritz, C., Saltzman, E., Stievenard, M., 1999. Climate and atmospheric history of the past 420000 years from the Vostok ice core, Antarctica. Nature 399, 429-436.

\section{[a]}

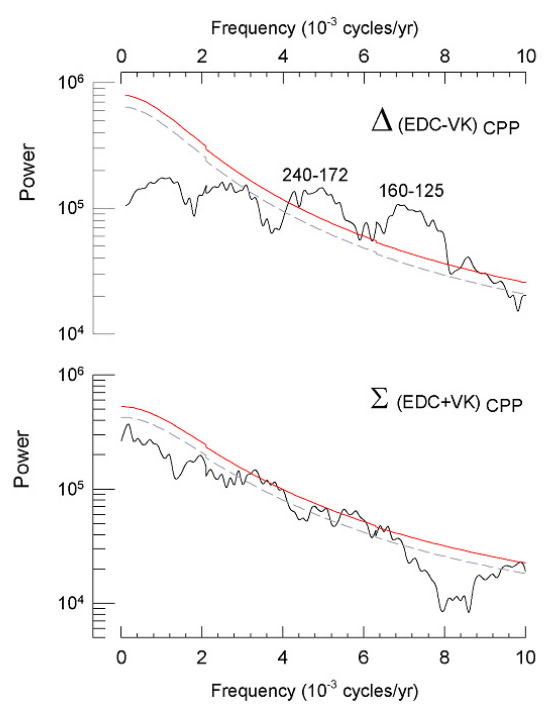

[b] [II]

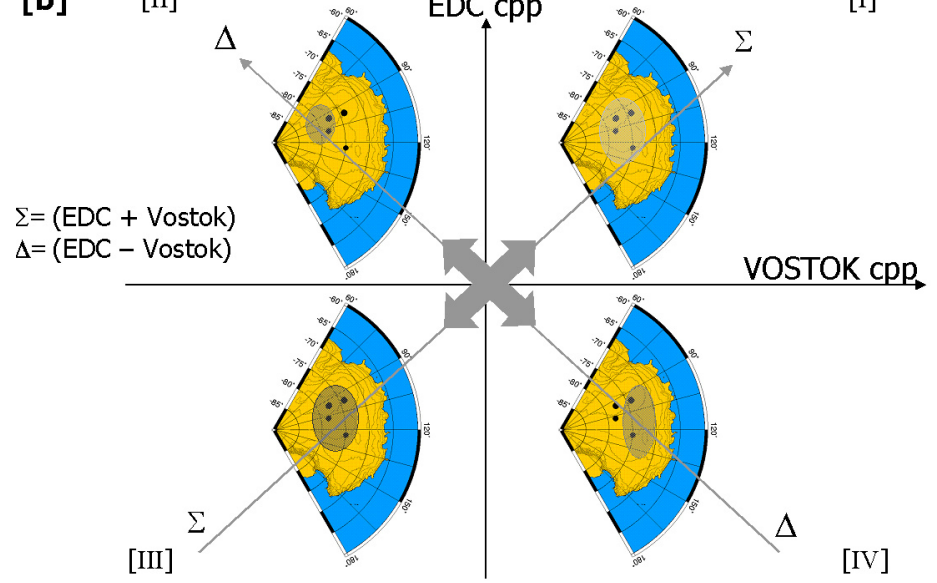

Fig 2: Symmetric and asymmetric modes of variability of atmospheric circulation over East Antarctica during the Holocene. (a): Spectral analysis (Multitaper Method) of the difference $\Delta$ (top) and the sum $\sum$ (bottom) of dust size parameter from EDC and Vostok. The $95 \%$ and $99 \%$ confidence levels with respect to a red noise signal are shown.

(b): Vostok CPP and EDC CPP dust parameters are represented by the $x$ and $y$ axes, respectively. The $60^{\circ} E-180^{\circ} \mathrm{E}$ sector of the East Antarctic Plateau with location of drilling sites is shown. The $\sum$ (sum) and $\Delta$ (difference) composite dust parameters are represented by the first and second diagonals. The arbitrarily rounded grey area represents the major centre of subsidence. Along the $\sum$ axis, is a symmetrical mode of variation from generally enhanced (quadrant III) to reduced (quadrant I) subsidence. Along the $\Delta$ axis (asymmetric mode), the area of subsidence varies from an eccentric location (quadrant IV) to a more poleward position (quadrant II). This may correspond to an atmospheric dipole over East Antarctica having a pronounced 200-year periodicity. Dots are locations of the drilling sites, clockwise from bottom right: EPICA Dome C, Vostok, Dome B and Komsomolskaya 